\title{
LA RELEVANCIA DE LOS CURSOS CAUSALES HIPOTÉTICOS EN LA IMPUTACIÓN NORMATIVA DEL RESULTADO A LA CONDUCTA IMPRUDENTE. SU SIGNIFICADO PRÁCTICO EN MATERIA DE RESPONSABILIDAD MÉDICA POR ERROR DE DIAGNÓSTICO
}

THE RELEVANCE OF HYPOTHETICAL CAUSAL COURSES AND THE NORMATIVE IMPUTATION OF HARMFUL EVENTS TO NEGLIGENT CONDUCTS: ESPECIAL REFERENCE TO MEDICAL MALPRACTICE CASES FOR DIAGNOSTIC ERRORS

\begin{abstract}
Andrea Perin*
RESUMEN: El estudio aborda la relevancia de los cursos causales hipotéticos para la imputación normativa del resultado a la conducta imprudente. Se exponen argumentos centrados en el perfil teleológico de las reglas de diligencia que concretan el deber de cuidado, defendiendo la adopción de los criterios del "aumento del riesgo" o bien, tratándose de supuestos de comisión por omisión, de la "disminución de oportunidades". Se aclara la relación dogmática entre dicha valoración y el criterio de la "realización del riesgo" (o "fin de protección de la norma"), reafirmando la correspondencia estructural entre los delitos comisivos y los "omisivos impropios". Finalmente, se pone especial énfasis en el significado práctico y político-criminal de la estructura dogmática defendida en materia de responsabilidad penal médica por error de diagnóstico.
\end{abstract}

Palabras clave: Delitos imprudente, mala praxis médica, nexo de riesgo, cursos causales hipotéticos, error de diagnóstico

ABSTRACT: The paper deals with the relevance of hypothetical causal courses for the imputation of harmful events to negligent conducts. The author focuses on the teleological profile of the "duty of care" in order to discuss the adoption of the "increase of risk" -or "decrease of chances"- ex post normative criteria. The discussion clarifies the relationship between the evaluation concerning the "realization of risk" (i.e. the "scope of protection" of the norm) and the consideration of the hypothetical lawful conduct. This allows reaffirming the structural correspondence between negligent "active conducts" and negligent "improper omissions". Finally, the paper considers the relevance of the defended theoretical structure by focusing on medical malpractice cases for diagnostic errors.

Key words: Criminal negligence, medical malpractice, risk link, hypothetical lawful conduct, diagnostic error

* Ph.D. in Comparative and European Legal Studies, Università degli Studi di Trento (Italia), y Doctor en Derecho por la Universidad del País Vasco/EHU (España). Profesor de Derecho Penal en la Universidad Andrés Bello, Facultad de Derecho. Dirección postal: Bellavista 0121, Santiago, Chile. Correo electrónico: andrea. perin@unab.cl. Estudio elaborado en el marco del proyecto Fondecyt de Iniciación Nº 11170924. 


\section{INTRODUCCIÓN AL PROBLEMA JURÍDICO Y PRESENTACIÓN DE LA TESIS DEFENDIDA}

¿Es oportuno castigar al autor de una conducta imprudente, mientras no sea posible afirmar con seguridad rayana a la certeza que el cumplimiento del cuidado debido hubiese evitado el resultado acaecido? ¿ $\mathrm{O}$ el abandono del criterio de imputación de la evitabilidad, en los delitos de resultado, supondría un retroceso no deseable a la lógica del versari in re illicita?

Como es sabido, esta cuestión ha generado un largo, intenso y complejo debate en el marco de la doctrina comparada. Según la teoría prevalente $(\$ \mathrm{~V})$, mientras no se pueda afirmar la evitabilidad del resultado, se impondría la absolución (in dubio pro reo). Por otra parte, algunos autores han defendido la teoría del "aumento del riesgo", o bien -tratándose de hipótesis de "comisión por omisión"- el criterio de la "pérdida de oportunidades" (retomaremos esta doctrina planteando nuestra hipótesis). Finalmente $(\$ \mathrm{VI})$, hay quienes han sostenido que la valoración de los cursos causales hipotéticos no tendría relevancia en el marco del juicio de imputación, siendo necesario y a la vez suficiente averiguar si el riesgo no permitido generado por la conducta se ha realizado en el resultado (o bien, si dicho resultado pertenece al ámbito de protección de la norma de cuidado infringida) ${ }^{1}$.

El principal elemento de complejidad -y, a menudo, de confusión- conceptual de esta discusión concierne a la relación dogmática que se establece entre el criterio del "fin de protección de la norma” (o bien, la valoración sobre la realización del riesgo no permitido generado por la conducta imprudente en el resultado), por un lado, y la consideración del curso causal alternativo-hipotético dado por la conducta conforme a la expectativa del derecho, por otro.

Según un planteamiento recurrente $(\$$ III), el criterio de la realización del riesgo en el resultado (en cuanto éste pertenezca al ámbito de protección de la norma de cuidado infringida) debería mantenerse separado del juicio sucesivo relativo a la idoneidad preventiva de la conducta alternativa-hipotética diligente. Desde esta óptica, mientras no se realice la segunda evaluación, aún no resultaría configurado aquel "nexo de riesgo" -esto es, aquel requisito de "causalidad de la imprudencia", según se denomine- que permite distinguir los supuestos de causación de un resultado lesivo a través de una conducta imprudente (todavía un versari in re illicita) de aquellos de causación del resultado por imprudencia (ya "hecho propio" de su autor material, o del garante, según sea el caso) ${ }^{2}$.

Sin embargo, nuestro objetivo consiste en poner en evidencia los límites de la exigencia "causalista" subyacente al criterio de la evitabilidad del resultado, para reconsiderar y defender la adopción del criterio -solo aparentemente menos garantista- del "aumento del riesgo" o "pérdida de oportunidades" (según se trate de conductas lesivas comisivas u omisivas).

\footnotetext{
${ }^{1}$ Sobre este debate, cfr.: Roxin (1962) pp. 411 y ss.; Roxin (1997) pp. 379 y ss.; UlsenheImer (1965); FrisCH (2004); Fiandaca (2006), pp. 945 y ss.; Summerer (2013); Gimbernat (2015), pp. 21 y ss.; Gimbernat (2017). En cuanto, en particular, a los delitos de "comisión por omisión": Gimbernat et al. (1994); Donini (1999) pp. 32 y ss.; Viganò (2009) pp. 1679 y ss.; LuZÓN (2017) pp. 145 y ss.

2 Cfr. Marinucci (1965) pp. 264 y ss.; Corcoy (1989) pp. 451 y ss.; Forti (1990) pp. 668 y ss.; Roxin (1997) pp. 373 y ss.
} 
Esta hipótesis general será planteada y defendida reflexionando sobre el perfil teleológico de las reglas de diligencia que concretan el deber de cuidado y la estructura bifásica del "nexo de riesgo" en el marco del tipo imprudente. En particular, expondremos cuatro $\operatorname{argumentos}^{3}$. (1) El primero consiste en reafirmar la correspondencia estructural de los delitos comisivos y omisivos impropios. (2) El segundo aclara que el criterio del "fin de protección de la norma”, por un lado, y la consideración de la conducta alternativa conforme a la expectativa del derecho, por otro, reflejan la misma exigencia de imputación; no obstante, la consideración del curso alternativo-hipotético mantiene una relevancia conceptual y práctica complementaria respecto del primero. (3) Enseguida, se ofrece una réplica al argumento crítico según el cual el abandono del criterio de "evitabilidad" supondría recaer en la lógica del versari in re illicita, haciendo del resultado lesivo una especie de "condición objetiva de punibilidad"; además, se consideran las doctrinas que abogan por la sustitución o integración del paradigma de intervención penal basado en delitos de resultado a través de la introducción de nuevos tipos de peligro, con especial referencia al riesgo de judicialización de la actividad médica y el fenómeno de la "medicina defensiva". (4) Finalmente, se aborda el problema de la "redescripción del resultado" objeto del juicio de imputación, destacando otro límite de la pretensión causalista subyacente a la doctrina prevalente.

\section{EL “NEXO DE RIESGO"Y LA IMPUTACIÓN NORMATIVA DEL RESULTADO A LA CONDUCTA IMPRUDENTE (UNA PERSPECTIVA "LAICA")}

Antes de desarrollar nuestros argumentos, cabe una aclaración de orden terminológico y conceptual.

Atendiendo a la literatura comparada, el estudio del nexo normativo entre la conducta imprudente y el resultado acaecido se enmarca en tópicos dogmáticos de variada denominación. Algunos autores se refieren al "nexo de antijuridicidad" o "nexo de riesgo", sobre todo en el marco teórico de la "imputación objetiva del resultado" ". Otros, en cambio, acuden preferentemente a las expresiones "causalidad de la culpa" , "causalidad de la lesión al deber de cuidado", u otras similares ${ }^{6}$.

\footnotetext{
${ }^{3}$ Los argumentos que se exponen en la $\$$ VII retoman algunas reflexiones planteadas en PERIN (2018a) pp. 28 y ss., donde se defiende el abandono de la exigencia de la "evitabilidad" para la imputación del resultado en los delitos omisivos impropios. Aquí, en cambio, se trata de corroborar la validez general de dicha solución; es decir, también a propósito de los delitos comisivos de resultado, y más allá de las contingencias de la experiencia italiana. Además, el estudio de la literatura chilena y comparada sobre la materia nos permite matizar y desarrollar aspectos relevantes a propósito del concepto de "imputación normativa", la estructura bifásica del nexo de riesgo, la exigencia causalista subyacente al criterio de la evitabilidad, la redescripción del evento lesivo objeto del juicio de imputación, y las implicaciones judiciales y político-criminales de la conclusión defendida.

${ }^{4}$ Cfr. entre otros: Roxin (1997) pp. 373 y ss.; Corcoy (1989) pp. 423 y ss.; Donini (2006) pp. 19 y ss., 37 y ss.

5 P. ej. Grotto (2012) pp. 207 y ss., 240 y ss.

${ }^{6}$ En sentido crítico y para más referencias, Puppe (2010) pp. 66 y ss.; Gimbernat (2015) p. 33.
} 
Perin, Andrea "La relevancia de los cursos causales hipotéticos en la imputación normativa del resultado ..."

Esta pluralidad terminológica se explica a la luz del debate dogmático entre sostenedores y detractores de la "moderne" objektive Zurechnungslehre ${ }^{7}$. Según ya han destacado algunos autores, los resultados dogmáticos presentados como propios por esta doctrina (en sus numerosas variantes) encontrarían, en realidad, su origen y razón normológica en la teoría normativa de la culpa (o imprudencia) ${ }^{8}$; esto es, en el estudio del "deber de cuidado". En efecto, alrededor de los años '60 de siglo pasado, el criterio del "fin de protección" de la norma fue valorado por aquella doctrina que, actualizando la teoría de la "adecuación" (teoría de la causalidad jurídica ${ }^{9}$, estrictamente relacionada, en su evolución, al concepto de "diligencia"10), y recuperando las teorías de la imputación objetiva de Larenz y Honig ${ }^{11}$, empezó a desarrollar la moderna teoría de la imputación objetiva del resultado ${ }^{12}$. Sin embargo, ese mismo aspecto de la relación entre la conducta imprudente y el resultado fue tratado también como parte fundamental de algunas de las más relevantes y acabadas concepciones normativas de la "culpa" (o "imprudencia") de mediados del siglo pasado, recuperando un criterio procedente del derecho civil ${ }^{13}$. En efecto, como escribió Giorgio Marinucci, "considerar típica una conducta por el simple hecho que (...) ésta haya infringido una norma de diligencia, llevaría a imputar (...) el resultado por el mero hecho de versar in re illicita" 14 .

7 Cfr. Gimbernat (1985-6) pp. 167 y ss.; Donini (1989) pp. 588 y ss., 1114 y ss.; Donini (2006); Castaldo (1989); Cancio (2001) pp. 261 y ss.; Mir (2003) pp. 1 y ss.; Carnevali (2008) pp. 223 y ss.; Rojas (2010) pp. 233 y ss.; HaAs (2016), pp. 1 y ss.

8 MarinuCCI (1991) pp. 3 y ss. Esta opinión ha sido avalada por MaIWALd (2018) pp. 8 y ss., 19-20, quien retoma la contribución polémica de Marinucci para aclarar que algunos criterios de “imputación objetiva” encuentran en realidad su razón y legitimación normológica en la teoría normativa de la imprudencia (o culpa). De forma semejante Robles (2015) p. 38.

9 Ver, p. ej., Bustos y HormazÁbal (1980-81) pp. 12-13, 25 y ss., 39; LÜbBe (1993) pp. 87 y ss.

10 Un cambio determinante para la noción de "adecuación” -y, según algunos autores, también para la "culpa”- se realizó en las contribuciones de Engisch, en las que el primer criterio deja de ser concebido de forma puramente estadística, siendo asociado expresamente al concepto de "diligencia": ENGISCH (1931) p. 59. Sin embargo, para lecturas contrastantes de dicha contribución y, en particular, a propósito de la controvertida anticipación de la culpa -su elemento "objetivo"- al plano del injusto, cfr.: Donini (1989) pp. 612 y ss., 617 y nota 93; FORTI (1990) pp. 139-140; MarinucCi (1991) pp. 8 y ss.; Marwald (2018) p. 18. Sobre la ubicación sistemática de la "adecuación”, entre la tipicidad y la culpabilidad: Bustos y Hormazábal (1980-81) pp. 26 y ss.

11 El primer intento de tratar la adecuación más allá de la perspectiva causal fue realizado por el filosofo del derecho y civilista alemán LARENZ (1927). Esta investigación fue recogida por el penalista HonIG (1930) pp. 174 y ss., para luego ser revalorada en sentido sistemático por Roxin (1970).

12 En la doctrina alemana, la necesidad de comprobar si el resultado es uno de aquellos que la norma infringida tiene el objetivo de evitar (siendo realización del riesgo no permitido generado por la conducta), además de la estrecha relación entre la previsibilidad del resultado y el fin de protección de la norma, fueron destacados, recuperando una idea de Engisch (Engisch (1931) p. 61, por Ulsenheimer (1965), y Rudolphi (1969) pp. 549 y ss. Dicho criterio fue valorado por GIMBERnat (1990) como base de su "reprochabilidad objetiva"; y en la contribución de Roxin (1970) pp. 132 y ss., empezó a asumir el papel de concepto sistemático general. En la literatura castellana, véase el estudio de FEIjóo (2001) pp. 151 y ss., 323 y ss.

13 Forti (1990) pp. 424-5, nota 190; MarinUCCI (1991) pp. 11-12; cfr. Rojas (2010) p. 242.

${ }_{14}$ MarinucCi (1965) pp. 57, 272 (trad. nuestra). Bajo la perspectiva de la culpa, también autores partidarios del paradigma presuntivo de la culpa in re ipsa habían mostrado como la responsabilidad por imprudencia debía limitarse a los resultados pertenecientes al ámbito o fin de protección de la norma infringida: así, BRICOLA (1960) p. 33, NOTA 54. 
Lo anterior contribuye a explicar por qué, tras la evolución dogmática del siglo XX, hemos presenciado una superposición conceptual y funcional evidente entre la teoría normativa de la imprudencia (en cuanto al estudio de dicho nexo causal-normativo entre la infracción y el evento), por un lado, y la imputación objetiva, por otro. Lo que ha generado un intenso debate acerca de la "paternidad" de los logros dogmáticos en cuestión ${ }^{15}$.

Debido a lo anterior, nuestra manera de abordar el asunto de la "tipicidad imprudente” pretende prescindir de la cuestión terminológica. En efecto, el enfoque metodológico que nos parece más conveniente adoptar consiste en centrar nuestras reflexiones en las cuestiones sustantivas subyacentes a las distintas denominaciones categoriales ("causalidad de la imprudencia", "imputación objetiva del resultado", etc.). Dichas cuestiones son las mismas, y las soluciones alternativas que se plantean, también. Por todo ello, optamos aquí por la expresión "imputación normativa" (en lugar de "objetiva"): una expresión "laica”, es decir, no partidaria de una u otra reconstrucción sobre la paternidad del "nexo de riesgo" en cuestión; y que, además, permite distinguir con claridad los problemas de causalidad (material) y de infracción del cuidado debido (ex ante), de aquellas de imputación del resultado a la conducta imprudente (según criterios normativos y juicios ex post) ${ }^{16}$.

\section{LA RELEVANCIA DE LOS CURSOS CAUSALES HIPOTÉTICOS EN LA ESTRUCTURA DEL TIPO IMPRUDENTE DE RESULTADO (EN LA DOGMÁTICA COMÚN)}

Centrémonos ahora de forma más detenida en el tratamiento dogmático de la cuestión.

En los delitos comisivos, la valoración de la eficacia impeditiva del "comportamiento alternativo diligente" representaría el último momento del juicio de imputación en el marco del injusto. Tras haber considerado y comprobado (1) la existencia del nexo de causalidad material entre la conducta y el resultado, (2) el incumplimiento del deber de cuidado a través de dicha conducta, y (3a) la pertenencia del resultado acaecido al ámbito de protección de la pauta de cuidado infringida, deberíamos preguntarnos (3b) qué hubiese pasado si el sujeto hubiera actuado conforme a la expectativa del derecho (con el cuidado debido).

Esta valoración debería realizarse en cuanto haya sido previamente confirmado que el modelo de previsión y prevención incorporado en la norma infringida (esto es, su "ámbito de protección") abarca el resultado acaecido (evento que, precisamente por ello, representa la realización del riesgo "no permitido" creado por la conducta) $)^{17}$.

15 Paradigmática es la disputa -sin demasiada trascendencia práctica- sobre la pertenencia del "principio de confianza" a la constelación de criterios de "imputación objetiva" (entre otros, MARAVER (2009)), o a la teoría normativa de la imprudencia (sin necesidad de acudir a la teoría de procedencia germánica: entre otros, MARINUCCI (1965) pp. 198-9).

16 Sobre la sobrevaloración de la imputación del resultado desde la perspectiva ex post, respecto de la subvaloración de la conducta según un juicio ex ante, FrISCH (2006) y RobLES (2006). Reflexiones análogas, en el marco de un estudio sobre la relación entre el "principio de confianza" (relevante desde una perspectiva ex ante) y el criterio de la "autopuesta en peligro de la víctima" (de imputación ex post), en Perin (2016a) pp. 18 y ss., 26-7.

17 Cfr. entre otros: Wolter (1981) p. 333; Corcoy (1989) pp. 473 y ss., 489 y ss.; Forti (1990) pp. 429, 446, 664; FeIjóo (2001) pp. 323 y ss., 330 y ss., aunque según este autor, el segundo juicio representa simplemente un límite negativo a la imputación del resultado; Grotto (2012) pp. 207 y ss.; Summerer (2013) pp. 275 y ss. 
En este sentido, se plantearían dos situaciones. La primera, que en ocasiones la regla de conducta resultaría ex post inadecuada para afrontar la situación de riesgo por la que había sido adoptada; y, de ser así, la interrupción del nexo de imputación se justificaría -antes aún- por la ausencia de la "realización del riesgo" en el resultado ${ }^{18}$. La segunda, dada por otros casos en que, de otro modo, la pauta de cuidado se tornaría ineficaz precisamente ante aquellos riesgos que, habiendo sido identificados ex ante por el modelo de prevención, habrían representado su ámbito de protección ${ }^{19}$. En esta segunda categoría de hipótesis, de no realizarse la pregunta acerca de la evitabilidad del resultado, aquel "nexo de riesgo" entre la conducta imprudente y el evento lesivo no podría valorarse normativamente existente, dada la imposibilidad de distinguir los casos de causación de un resultado a través de una conducta imprudente (todavía un versari in re illicita) de aquellos de causación de un resultado por imprudencia (ya un hecho penalmente "propio" del autor).

También en los supuestos de comisión por omisión ${ }^{20}$, el juicio hipotético-pronóstico aludido representaría, desde la perspectiva sistemática común, el último paso del juicio de imputación en el marco del injusto. Pero con una diferencia fundamental. La valoración sobre la eficacia impeditiva de la conducta alternativa diligente del garante como momento de imputación normativa se identifica aquí con el requisito de la "causalidad omisiva" o "hipotética"21. En efecto, solo preguntándonos qué hubiese pasado si el garante hubiera actuado de forma cuidadosa sería posible establecer un nexo lógicamente causal entre la omisión (la no realización de la conducta debida) y el resultado que se le pretende imputar ${ }^{22}$.

\section{LA DISTINCIÓN ENTRE REGLAS DE CUIDADO "PROPIAS" E "IMPROPIAS". ALGUNOS CASOS PARADIGMÁTICOS}

Desde la perspectiva explicada en el apartado anterior, expresión de una configuración que podríamos considerar consensuada (o por lo menos recurrente en la literatura), se ha destacado que tanto en las hipótesis comisivas como en las omisivas impropias, el juicio sobre la idoneidad preventiva del comportamiento alternativo diligente asumiría una relevancia autónoma según el modelo de previsión y prevención incorporado por la norma de

Diferente en cambio el planteamiento sistemático de GARRIDo (1997) Tomo III, pp. 191 y ss., quien, en cuanto a los delitos omisivos impropios, invierte el orden de los dos criterios mencionados. Con especial referencia a la aplicación de este criterio en la jurisprudencia chilena y en materia de responsabilidad médica, VARGAS (2017) pp. 105-107.

18 Forti (1990) pp. 664-5; VenEZiani (2003) pp. 85 y ss.

19 Forti (1990) pp. 665-6. Véase también Summerer (2013) pp. 287 y ss., 299 y ss., 311 y ss.

20 Sobre la fundamentación de la imputación por "comisión por omisión”, en este medio, Carnevali (2002) pp. 69 y ss.; HernÁNdez (2011) pp. 21 y ss.; Contesse (2017) pp. 16 y ss., 32 y ss.

21 En este sentido y entre otros, haciendo referencia a la naturaleza "normativa" del problema de imputación subyacente a la denominada "causalidad omisiva", RoJAs (2008) pp. 192-3.

22 Sobre la noción de "causalidad" aplicada a los delitos de comisión por omisión, entre otros y para más referencias: Bustos y HormazÁbal (1980-81) pp. 23-24, 32; Garrido (1997) Tomo III, pp. 190-1; Donini (1999) pp. 32 y ss.; Puppe (2010) pp. 81 y ss.; Bartoli (2010) pp. 47 y ss.; Luzón (2017) pp. 155 y ss.; Náquira (2017) Tomo II, pp. 469-470. 
diligencia $^{23}$. Acudiendo a una distinción planteada en la doctrina, dicha relevancia dependería del carácter "propio" o "impropio" de la regla de conducta en consideración ${ }^{24}$.

Piénsese en el caso del conductor de un vehículo que atraviesa el cruce no obstante se encuentre el semáforo con luz roja, ocasionando un accidente, y provocando de esta forma la muerte de otro conductor en tránsito con luz verde. Ante un supuesto de esta naturaleza, no cabe duda de que tanto el nexo de causalidad material como la infracción del cuidado debido existen; asimismo, el resultado acaecido representa la realización del tipo de riesgo que la regla infringida (el signo "pare") tenía por objetivo evitar. La norma inobservada remite a una regla "propia", pues asegura evitar todo resultado perteneciente a su ámbito de protección $^{25}$. Con lo cual, una vez averiguada la correspondencia entre el resultado acaecido y el tipo de resultado indicado por dicho ámbito de protección, no sería necesario indagar, además, qué hubiese pasado si el autor hubiese cumplido el deber de cuidado. En efecto, resulta evidente a primera vista que el resultado no se hubiera realizado con toda seguridad.

Piénsese ahora en la siguiente reformulación del caso de la novocaína ${ }^{26}$. Supongamos que la regla infringida sea la lex artis que requiere conocer la tolerancia del paciente al anestésico ${ }^{27}$. Desde esta perspectiva, el resultado se puede considerar imputable tanto ex ante como ex post, pues el fallecimiento del paciente recaería en el ámbito de protección de una norma de cuidado que, como en el caso anterior, se debería poder considerar como "propia”. Por ello, la conducta cuidadosa (alternativa-hipotética) del facultativo habría evitado la muerte del paciente con toda seguridad ${ }^{28}$.

En otros casos, en cambio, el criterio del "fin de protección de la norma" no sería capaz de absorber la valoración acerca de la idoneidad preventiva de la conducta alternativa diligente. En efecto, pese a la (aparente) realización del riesgo (no permitido generado por la conducta) en el resultado, no es posible comprobar si la conducta conforme a la expectativa de diligencia esperada hubiese permitido evitarlo.

23 La "norma" de cuidado es la norma penal prevista en los tipos penales: CorCoy (1989) p. 102. No obstante, en ocasiones -por ejemplo, cuando se habla de "fin de protección de la norma"-, la doctrina superpone dicho concepto al de "deber de cuidado": así, por ejemplo, Feıjóo (2001). Sin perjuicio de lo anterior, por "deber" de cuidado ha de entenderse aquella expectativa de comportamiento, basada en dicha norma penal, cuya infracción puede justificar, aunque no por sí sola, la imputación de responsabilidad por imprudencia. El deber de cuidado, a su vez, se concreta en pautas o "reglas" de diligencia, prudencia y pericia, atendiendo a las características de cada caso concreto (tipo de actividad, parámetro normativo de referencia, etc.) y la eventual disponibilidad de estándares técnicos pre-determinados (por protocolos, reglamentos, guidelines médicas, etc.). En sentido similar, CASTRONuOvo (2009) pp. 287-289; VARGAS (2017) pp. 29 y ss., 37 y ss. Más referencias sobre los criterios de concreción del deber de cuidado en pautas o reglas de diligencia, en PERIN (2017) pp. 211 y ss.

24 Veneziani (2003) pp. 15 y ss. Considera válida dicha distinción también Donini (2004) p. 109.

25 Han sido definidas "propias" las reglas de cuidado "basadas en un juicio de previsibilidad del resultado y segura (= con probabilidad rayana en la certeza) evitabilidad de éste a través del comportamiento alternativo lícito": VenEZIANI (2003) p. 15.

26 Según la versión considerada por la doctrina, el médico inyectó cocaína en vez de novocaína y el paciente falleció; sin embargo, aunque se hubiese aplicado el anestésico adecuado, el paciente hubiese fallecido por una intolerancia a dicha sustancia.

27 V. ad es. Hava (2002) p. 176; y Eb. Schmidt, citado por Castaldo (1989) p. 103, según el cual el médico debía considerarse culpable, siendo previsible la muerte del paciente, tanto usando cocaína como novocaína, pues hubiera tenido que abstenerse de usar cualquier anestésico.

28 Considera esta posible lectura alternativa del caso también MarTínez (1992) p. 196. 
Piénsese en el siguiente supuesto comisivo $^{29}$. Un evento sísmico de gran magnitud provoca el derrumbe de un edificio y el fallecimiento de $n$ personas. Se demuestra que los estándares establecidos por la ley de construcción no se cumplieron al pie de la letra. Sin embargo, la defensa del ingeniero responsable del proyecto de construcción, acusado de homicidio imprudente, alega el siguiente argumento: dada la intensidad del terremoto, no es posible saber si actuando en cumplimiento exacto de las leges artis en materia de construcción, el evento se hubiese evitado. Es decir: si bien -al menos aparentemente...- el resultado pertenezca al ámbito de protección de las normas infringida (pues las reglas técnicas establecidas por la ley de construcción tienen el objetivo de evitar precisamente resultados de esa naturaleza), no es posible establecer si el resultado es consecuencia de las insuficiencias constructivas.

Algo parecido sucede en el siguiente supuesto de comisión por omisión. La víctima de un accidente de tráfico sufre graves lesiones al hombro derecho que requieren una intervención urgente para reducir las fracturas. La intervención de recomposición resulta exitosa, pero durante el primer control postoperatorio el paciente muestra señales de una posible distrofia muscular en correspondencia de la lesión: se trataría de un curso causal actual dirigido a un resultado por ende previsible, una lesión irreversible del tejido muscular. Sin embargo, el cirujano no realiza ninguna prueba diagnóstica para averiguar las causas de dichos síntomas y la degeneración de tejido muscular se vuelve en poco tiempo irreversible, confirmando la presencia de una lesión de nervio periférica (no detectada a tiempo). Ante los cargos por lesiones imprudentes, la defensa del acusado alega el siguiente argumento: no es posible establecer qué hubiese pasado si el facultativo hubiera realizado un diagnóstico tempestivo, pues las estrategias terapéuticas disponibles para casos clínicos de ese tipo no aseguran el éxito del tratamiento; en cambio, se agrega, lo más probable es que, de todos modos, cualquier prueba diagnóstica e intervención tempestiva no hubiese permitido evitar la lesión definitiva e irreversible sufrida por el paciente.

Los últimos casos se caracterizan por incumplimientos de pautas de cuidado de carácter "impropio", es decir, reglas de conducta que no aseguran la evitación de todo resultado perteneciente a su ámbito de protección ${ }^{30}$. Por ello, ante la pregunta sobre qué hubiese pasado si el sujeto hubiese actuado de forma cuidadosa, se plantea la cuestión acerca de qué criterio sería oportuno adoptar para poder afirmar la existencia de la relación de riesgo entre la conducta imprudente y el resultado.

\footnotetext{
29 Parecido a otro, comentado por MAYer y Vera (2015). Aunque en esa ocasión la defensa no planteó la cuestión objeto de nuestras reflexiones: se alegó la supuesta atribución de responsabilidad objetiva (ver los $\$ \$ 3.1$ y 3.2 de la contribución citada), pero sin destacar el problema de la -posible duda acerca de la- evitabilidad del resultado.

30 Veneziani (2003) p. 15. Sin embargo, nos haremos cargo de matizar esta noción en el § VII.2.
} 


\section{LA TESIS DE LA EVITABILIDAD}

La doctrina prevalente, tanto en este medio como en el marco del derecho comparado, defiende el criterio de la evitabilidad. Conforme a dicho criterio, mientras no se compruebe que el perjuicio no se hubiese producido si el agente hubiese actuado conforme al comportamiento jurídicamente esperado, el resultado no se le puede imputar al causante imprudente (o al sujeto garante a quien corresponda debido al alcance de su posición jurídica calificada) $)^{31}$.

Sin embargo, es preciso distinguir. En efecto, mientras que algunos autores defienden el carácter irrenunciable de la evitabilidad como criterio general (asumiendo que, en todo caso, el resultado tiene que ser previsible y evitable ${ }^{32}$ ), otros prefieren distinguir según se trate de delitos comisivos u omisivos.

En los delitos comisivos, la valoración de la evitabilidad permitiría establecer la existencia de la relación de riesgo entre la conducta imprudente y el resultado, sin perjuicio de que la relación de causalidad (material) haya sido previamente comprobada. En cambio, cuando se trate de delitos de comisión por omisión, el nexo de causalidad omisivo hipotético podría estimarse normativamente existente sólo en la medida en que se pueda argumentar que la intervención del garante hubiese evitado el resultado lesivo ${ }^{33}$.

Considerando lo anterior, y según defiende un sector de la doctrina, mientras que en los supuestos de culpa comisiva "la duda sobre la evitabilidad del resultado no excluye que la causación de este pueda ser considerado como hecho propio del sujeto" ${ }^{34}$, en los supuestos de omisión impropia, en cambio, siempre sería necesario verificar la evitabilidad del resultado; de otra manera, la asunción de criterios menos exigentes supondría renunciar al nexo de causalidad entre la conducta omisiva y el resultado ${ }^{35}$.

Esta orientación se basa, en primer lugar, en la siguiente consideración: la responsabilidad omisiva es más gravosa que la comisiva, pues, mientras que con esta el ordenamiento jurídico prohíbe realizar conductas lesivas, aquella le obliga al sujeto garante activarse para (tratar de) evitar que los cursos causales que atraviesen su ámbito de control y protección desemboquen en resultados dañinos ${ }^{36}$.

En este mismo sentido, además, se considera como la estructura de los delitos de comisión por omisión no cuenta con aquel nexo de imputación fuerte dado por la relación de

31 Entre otros, UlSENheimer (1965) pp. 146 y ss.; Frisch (2015) pp. 94 y ss., 98-99; en este medio, Mañalich (2015) pp. 26 y ss.

32 Así, Politoff et al. (2003) pp. 199-200, 282, 285-287.

33 Rojas (2018) p. 732, según el cual, con la doctrina dominante, la verificación del nexo de causalidad se basa en un "juicio de probabilidad rayana en la certeza de evitación del resultado en el evento hipotético de realización de la acción impeditiva”.

34 Donini (1999) pp. 41 y ss., 44; cfr. SChÜNemann (1975) pp. 647 y ss.

35 Donini (2011) pp. 533-5; Grotto (2012) pp. 230-234. Pese a rechazar la expresión "causalidad omisiva", estiman irrenunciable la prueba de la evitabilidad, entre otros: MuÑoz y GarCía (2010) pp. 243-4; ANGIONI (2006) p. 1311.

36 Sobre la naturaleza de la pretensión subyacente a la incriminación de la omisión: SGUBBi (1975); FiandaCA (1979); Novoa (1984); CADoppi (2011) pp. 1311 y ss.; NAVAS (2015) pp. 683 y ss.; ConTesse (2017) pp. 16 y ss.; ROJAS (2018) pp. 682 y ss. 
causalidad material entre la conducta y el resultado. Por ello, también autores conscientes de la probatio diabolica que muy a menudo supone la exigencia de la evitabilidad, así como de la "necesidad de un equilibrio entre el desvalor de la conducta y de resultado (...) hacia la superación del objetivismo del daño" ${ }^{\text {"37 }}$, sostienen que el requisito dado por la causalidad omisiva debe exigir la evitabilidad del resultado.

En suma, la exigencia de la evitabilidad representaría un presupuesto irrenunciable desde la óptica del sujeto a quien incumbe el deber del garante; y aún más irrenunciable en los delitos omisivos que en aquellos comisivos.

\section{LA TESIS DE LA NO RELEVANCIA DE LOS CURSOS CAUSALES HIPOTÉTICOS A EFECTOS DE LA IMPUTACIÓN}

Frente a la doctrina de la evitabilidad (y a quien defiende el criterio alternativo del "incremento del riesgo", según veremos en el $\$$ VII), algunos autores han defendido la no relevancia de los cursos causales hipotéticos para imputar el resultado a la conducta imprudente ${ }^{38}$.

El punto de partida de esta orientación consiste en señalar algo incontestable: desde un punto de vista lógico, la teoría de la evitabilidad es una adaptación de la condicio sine qua non. Una diferencia consiste en la operación mental requerida, siendo que, en vez de suprimir la conducta realizada, se exige añadir mentalmente una situación irreal, la realización de la conducta hipotética conforme al derecho; además, la valoración del curso hipotético buscaría establecer un nexo normativo, no material, entre la conducta imprudente y el resultado de quo. Pero, en ambos casos, se trata de juicios igualmente contra-factuales y condicionalísticos.

Sin embargo, se agrega que la teoría de la evitabilidad no logra lo que pretende conseguir, esto es, establecer una conexión realmente condicionalística, aunque normativa, entre la conducta infractora y el resultado. Y esto quedaría demostrado por el hecho de que los propios partidarios del planteamiento prevalente acaban conformándose con probabilidades más o menos elevadas ${ }^{39}$, aceptando de este modo un canon argumentativo claramente "arbitrario" 40 .

Frente a dicha contradicción, esta segunda doctrina hace coincidir la valoración del nexo de riesgo con el primer momento del juicio de imputación ex post: es decir, el juicio centrado en el ámbito de protección de la regla de cuidado infringida. En efecto, dado que "el resultado no es otra cosa que la concreción del desvalor de la acción", lo único que quedaría por demostrar, para establecer el nexo de antijuridicidad entre la conducta imprudente y el resultado, sería que el riesgo generado por la primera se haya manifestado en el

\footnotetext{
37 El mismo Donini (2011) P. 534.

38 Martínez (1994) pp. 105 y ss.; De Vero (2006) pp. 1508 y ss., 1511.

39 Entre ellos, en materia de comisión por omisión: Garrido (1997) Tomo III, pp. 190-1, quien destaca que "este juicio es hipotético, de probabilidades"; Grasso (1983) pp. 405 y ss. Otras referencias en LuZÓN (2017) pp. y 163 ss. En sentido crítico, Gimbernat (2015) pp. 27-28.

40 Stella (1988) p. 1256. De forma semejante Gimbernat (1994) pp. 27 y ss., 41-2. Cfr. las consideraciones problemáticas de Grasso (1983) pp. 385 y ss., quien, sin embargo, asume la tesis de la evitabilidad frente a la alternativa del "aumento del riesgo" (405 y ss.).
} 
segundo; en otras palabras, averiguar si el resultado final "era de aquellos que la norma de cuidado infringida tenía por misión evitar o reducir, o de aquellos en consideración de los cuales la conducta estaba prohibida" 41 .

En este sentido, también cuando se trate de delitos omisivos, para imputar el resultado a la conducta imprudente sería suficiente verificar que el "foco de peligro", "por encima del riesgo permitido a consecuencia de la no aplicación de medidas de precaución”, se haya concretado en el resultado típico. De este modo, "a la persona que incumple su obligación de controlar originaria o posteriormente (de forma permanente o periódica) el foco, entrando éste en la esfera del riesgo prohibido y causando un resultado típico, se le imputará ese resultado en comisión por omisión, en cuanto que es ella la responsable normativa (de haberse adoptado las medidas de precaución omitidas, el foco habría seguido siendo uno permitido) de la situación antijurídica creada” ${ }^{42}$.

\section{LA "IMPUTACIÓN NORMATIVA" DEL RESULTADO SEGÚN LOS CRITERIOS DEL "INCREMENTO DEL RIESGO" Y LA “PÉRDIDA DE OPORTUNIDADES"}

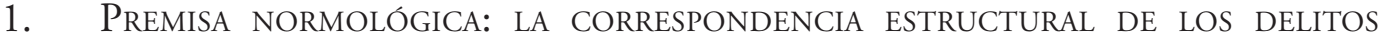 COMISIVOS Y OMISIVOS IMPROPIOS}

Frente a los planteamientos causalistas, el criterio del incremento del riesgo fue defendido por Claus Roxin en cuanto idóneo para evitar absoluciones no deseables desde el punto de vista político-criminal (cuando hubiese faltado la prueba de la evitabilidad), evitando al mismo tiempo recaer en la lógica del versari in re illicita (esto es, la imputación de resultados por infracción de normas de cuidado sin relación de riesgo con el daño $)^{43}$.

Se buscaba un punto de equilibrio hacia una solución de compromiso capaz de conjugar las instancias político-criminales de intervención penal con las garantías básicas del derecho penal liberal. Sin embargo, esta doctrina se expondría a una crítica fundamental, pues supondría una vulneración del principio in dubio pro reo y la subrepticia transformación de los delitos de resultado en delitos de peligro ${ }^{44}$. Este argumento crítico refleja la ratio subya-

41 Martínez (1994) p. 106. De forma semejante, Puppe (2010) pp. 104-105.

42 Gimbernat (1994) pp. 45, 53. Este planteamiento fue defendido comentando críticamente un caso decidido por el Tribunal Supremo español en el año 1989, en el que el médico no diagnosticó correctamente una peritonitis que llevó al fallecimiento del paciente. Así argumentó el Tribunal: “(..) dentro del mundo de las probabilidades no puede de ninguna manera descartarse (...), teniendo en cuenta la edad juvenil del enfermo (...) y las técnicas médicas y sobre todo quirúrgicas, el éxito de una intervención de este tipo, a tiempo. Afirmar esto no es incidir en una presunción, conjetura o sospecha, sino llevar a cabo una inferencia coherente con la lógica, con lo que no cabe duda de que, aun cuando concurrieran en el hecho fatal de la muerte, como es normal, una serie de concausas, le conducta del procesado fue contribuidora decisiva del acontecimiento (...). La actuación del médico procesado (...) contribuyó con su actuación a un resultado que era previsible y también evitable, dentro de la relatividad con la que estos conceptos han de manejarse en el campo del Derecho y especialmente del Derecho penal".

43 Roxin (1962) pp. 431 y ss.

44 Entre otros, Frisch (2015) pp. 98-99. Sobre esta crítica, Gimbernat (2015) pp. 39 y ss., 56 y ss.; LuZÓn (2017) pp. 167 y ss. Véanse también las réplicas del propio Roxin (1997) pp. 381 y ss. 
cente al criterio de la evitabilidad, cuya función sería asegurar que el resultado lesivo se impute en cuanto ocasionado por (o bien, debido a) imprudencia, y no simplemente a través (por medio) de una conducta imprudente. Además, en cuanto a los delitos de comisión por omisión, la valoración de la idoneidad impeditiva de la conducta alternativa diligente garantizaría la existencia de la relación causal entre la omisión y el evento no evitado ${ }^{45}$.

No obstante, frente a la postura crítica indicada, nuestra opinión es que la valoración de los cursos causales hipotéticos debería ser sustraída, también en los delitos omisivos impropios, del plano de la causalidad, y considerada -como ya sucede en los delitos comisivos- como momento de la imputación normativa del resultado ${ }^{46}$.

Solo preguntándonos "qué hubiese pasado si el garante hubiera actuado de forma cuidadosa" sería posible establecer un nexo lógicamente causal entre la omisión (mejor, la infracción) y el resultado que se le pretende imputar. Pero el primer nivel de imputación, en la estructura del tipo de comisión por omisión, se cumple averiguando si el resultado de quo pertenece al ámbito de control o protección de la posición de garante. Este -y no otroes el momento de la imputación que se debe considerar normativamente equivalente al nexo de causalidad material de los delitos $\operatorname{comisivos}^{47}$. En otros términos: el requisito que en los delitos comisivos se cumple averiguando la existencia de una relación causal entre la acción y el resultado, en los delitos omisivos impropios consiste en la pertenencia del resultado de quo al ámbito de protección de la posición de garante (y del correspondiente deber jurídico de activación $)^{48}$.

Distinta es, en cambio, la cuestión subyacente a la imputación del resultado a la conducta infractora (causal e imprudente). Este tercer nivel o momento de la imputación ${ }^{49}$ requiere haber valorado previamente el carácter de por sí imprudente de la conducta, según un juicio ex ante (segundo nivel del mismo juicio de imputación); y se realiza valorando la existencia de una relación normativa cuyos términos son, por un lado, la infracción del cuidado debido y, por otro, un resultado del "tipo" al que pertenece el resultado hic et nunc ${ }^{50}$.

Lo que se suele denominar "causalidad omisiva" pertenece en realidad a este tercer momento de imputación normativa: el nexo de riesgo. Por una razón lógica: pues requiere haber previamente valorado el carácter imprudente de la conducta. Por ende, no hay razones para seguir tratando la misma cuestión de imputación de forma diferente, según se trate de delitos comisivos u omisivos. La única diferencia estructural entre los tipos comisivos y omisivos impropios consiste en que, mientras que los primeros exigen una relación causal efectiva entre la conducta y el resultado, los segundos requieren averiguar si el evento de

\footnotetext{
45 Entre todos, Grasso (1983) pp. 405 y ss. Para más referencias, Gimbernat (1994) pp. 49 y ss.; Luzón (2017) pp. 170 y ss., 214 ss.

46 Cfr. p. ej.: Corcoy (1989) pp. 407 y ss., 451 y ss.; Muñoz y García (2010), pp. 243-4; Fiandaca (2006) 952 y ss.; VigANÒ (2009) pp. 1697-8, 1701-2, 1705 y ss.; LUZÓN (2017) p. 165.

47 Perin (2018a) pp. 24 y ss.

48 Cfr. el estudio histórico-dogmático (y crítico a propósito de la posición de garantía) de RojAS (2018) pp. 690 y ss., 717 y ss.

49 Cfr. de nuevo y en sentido similar, destacando con claridad los tres elementos de la estructura tripartida del tipo de omisión, Rojas (2008) pp. 192 y ss.

50 Nos centraremos en el problema de la “redescripción del resultado" en el $\$$ VII.4 de esta contribución.
} 
quo pertenece al ámbito de protección de la posición de garante. En este sentido, se puede decir que la causalidad material, de los primeros, es normativamente equivalente a la pertenencia del tipo de resultado a la posición de garante, en los segundos ${ }^{51}$.

2. Precisiones conceptuales a propósito de las reglas de Cuidado "impropias": LA RELACIÓN ENTRE LOS DOS MOMENTOS DEL “NEXO DE RIESGO”

La reubicación sistemática defendida en la sección anterior permite centrarnos en el perfil teleológico de la pauta de cuidado incumplida -su "fin de protección"-, con el objetivo de esclarecer la relación entre los dos criterios de “imputación normativa” (según la doctrina presentada en el $\$$ III).

Piénsese de nuevo en el supuesto de error de diagnóstico ( $\$$ IV), ante el cual no podemos establecer qué hubiese pasado si el facultativo hubiese realizado un diagnóstico correcto y tempestivo, pues las estrategias terapéuticas disponibles no aseguran el éxito del tratamiento, sino $x$ posibilidades de éxito, en casos clínicos similares. De la misma forma, recordemos el ejemplo del terremoto: aun tratándose de una conducta comisiva (indudablemente condicio sine qua non del resultado), no sabemos qué hubiese pasado si se hubiesen cumplido los estándares de construcción.

Ante supuestos semejantes - esto es, cuando el deber de cuidado se concrete en pautas o estándares inidóneos para asegurar, en todo caso y bajo cualquier circunstancia, la evitación del resultado-, el criterio de la evitabilidad del resultado nos llevaría a sentencias de absolución. Lo que supondría reconocer el carácter irrelevante del cuidado exigible ex ante a efectos de imputación ${ }^{52}$.

Cabe entonces una aclaración fundamental a propósito de la distinción conceptual señalada en el $\$$ IV. La noción de regla de cuidado “impropia” tiene carácter relativo y refleja, en realidad, un problema de aproximación e ignorancia. En efecto, cabe definir "impropio" un estándar de cuidado solo en el sentido de reconocer que realmente no sabemos si el caso concreto pertenece al conjunto -idealmente cerrado- de aquellos respecto de los cuales la misma pauta sería eficaz, y, por ende, "propia".

En nuestro ejemplo de mala praxis médica, sabemos que la realización de cierta modalidad de rehabilitación podría permitir evitar la degeneración irreversible del tejido muscular; pero lo que realmente no sabemos es si las características de aquel trauma (del caso clínico en cuestión, hic et nunc, con todas sus peculiaridades, incluidas las características fisiológicas del paciente como individuo único e irrepetible) permiten que la terapia resulte eficaz.

Esta consideración muestra el fundamento teórico, pero a la vez el límite práctico, de la tesis de la "no relevancia" de los cursos causales hipotéticos a efectos de imputación $(\$$ VI). Quien defiende que sería suficiente averiguar si el resultado de quo pertenece al ámbito

51 En sentido parecido VIGANÒ (2009) pp. 1709 y ss. A propósito del concepto de "comisión por omisión" y la equivalencia -o "identidad”- estructural con la comisión activa, véanse también las precisiones normológicas de Silva (2003) pp. 450 y ss., 463 y ss., 471 y ss. Acerca de su equivalencia también valorativa, CuADrado (1997) pp. 391 y ss., 398-399, 413 y ss.

52 De forma parecida ya Roxin (1962) p. 434 y Viganò (2009) pp. 1687-8. 
Perin, Andrea "La relevancia de los cursos causales hipotéticos en la imputación normativa del resultado ..."

de protección de la norma infringida, parte de una observación dogmática coherente (y subestimada en el marco de este debate): "el criterio del fin de la norma de cuidado no complementaría el principio de la evitabilidad o del incremento del riesgo, sino que lo sustituiría" 53. Sin embargo, en los supuestos en los que el deber de cuidado se concreta en una regla de cuidado "impropia" no resulta posible definir con precisión el ámbito de protección de la norma y, por ello, tampoco establecer si realmente el resultado acaecido representa la realización del "riesgo típico" (es decir, del grupo idealmente cerrado de riesgos) que la pauta incumplida tenía el objetivo de evitar. En estos casos no se puede verificar si la relación normativa indicada por el criterio del "ámbito de protección" (y de la "realización del riesgo en el resultado") subsiste realmente ${ }^{54}$.

En el caso de error de diagnóstico, pese a la previsibilidad del resultado (del tipo de resultado), no es posible saber -antes aun de preguntarnos qué hubiese pasado si el facultativo hubiese actuado conforme a la lex artis- si el modelo de prevención que debiese cumplirse incluye en su ámbito de protección (esto es, el conjunto ideal de casos clínicos respecto de los que resultaría eficaz) también el caso clínico de quo.

En suma, la distinción entre reglas de cuidado "propias" e "impropias" refleja una aproximación justificada como expresión de la imposibilidad de definir exactamente el ámbito de protección de la norma (es decir, el conjunto de resultados incluidos en ello). Toda regla de cuidado es "propia" respecto de su ideal, pero a menudo indeterminable, ámbito de protección; pero puede resultar "impropia" respecto al conjunto indeterminable de resultados (riesgos, cursos causales hipotéticos, etc.) que debería enfrentar.

\section{Sobre la SUpuesta "MANipulación" del paradigma de Resultado: VAloración POLÍTICO-CRIMINAL, CON ESPECIAL REFERENCIA AL FENÓMENO DE LA "MEDICINA DEFENSIVA"}

A la luz de lo anterior, debemos ahora hacernos cargo del argumento crítico esgrimido por quienes sostienen que la asunción del criterio del "incremento del riesgo" o de la "pérdida de oportunidades" - según se trate de delito comisivo u omisivo impropio- respondería a la necesidad de eludir un problema probatorio, consistiendo en una manipula-

\footnotetext{
53 En estos términos Martínez (1994) p. 107 (cursiva original). De forma semejante Puppe (2010) p. 105.

54 Este aspecto se ve reflejado en la consideración de FeIjóo (2001) p. 331, quien destaca que la "constatación hipotética de que una conducta correcta habría evitado el resultado puede estar relacionada en el caso concreto con factores causales ajenos a la norma de cuidado". A este propósito, señala Frisch (2015) p. 89, que en los supuestos en los que "el resultado se hubiera producido igualmente en caso de darse el así llamado comportamiento alternativo conforme a Derecho (...) falta la realización del riesgo desaprobado o la realización de la infracción del deber de cuidado en el resultado (...)". Por ello, faltaría también la "posibilidad de imputar el resultado (como injusto). En realidad, se ha realizado sencillamente un riesgo residual general (...); el que el autor haya actuado de manera desaprobada carece de significado normativo para el resultado acaecido -su producción se puede explicar al margen del comportamiento defectuoso del autor-". Cfr., en cambio, el replanteamiento de la teoría del incremento del riesgo defendido por SCHÜNEMANN (1975) p. 652, quien más que a una comparación de riesgos, se refiere a un juicio que supone averiguar si la norma establecida ex ante puede ser considerada eficaz también ex post frente al riesgo que se realice cierto tipo de resultado; así el propio RoxiN (1997) pp. 381-2, 385-6, quien rechaza que la teoría del fin de protección pueda sustituir la teoría del incremento del riesgo, siendo dichas teorías "complementarias".
} 
ción ilegítima de la estructura del delito de resultado y de sus requisitos de imputación ${ }^{55}$. En efecto, más allá del problema de la "causalidad omisiva" (ya aclaramos que se trata de una cuestión de imputación normativa), el peligro consiste en recaer en la lógica del versari in re illicita, haciendo del resultado una especie de condición objetiva de punibilidad.

Sin embargo, la consideración político-criminal que permite justificar el supuesto atajo probatorio consiste en respaldar el argumento subyacente a la oportunidad de asegurar la vigencia de ciertos modelos preventivos, en cuanto objetivamente exigibles, y aun sin ámbito de protección claramente definido ${ }^{56}$. Pero esto, no sólo porque de lo contrario tendríamos que "renunciar a toda exigencia de cuidado precisamente en los supuestos en que se requiere un cuidado especialmente grande" 57 ; sino más bien, y desde una óptica garantista, para evitar que se fijen estándares de cuidado ajustados de forma instrumental (i.e. funcional) a la segura (o más probable) evitabilidad del resultado. En efecto, frente al vacío de protección que podría generarse por la aplicación rigurosa del criterio de la "evitabilidad", los tribunales de justicia podrían ser inducidos a objetivizar y elevar aun más ciertos estándares de cuidado.

Piénsese en el ejemplo del terremoto. Si, como defiende un sector de la doctrina, el estándar de cuidado coincidiera con el parámetro de la "mejor tecnología" disponible en un momento histórico dado, bien podría fijarse en el marco del juicio un cuidado debido ajustado a estándares más exigentes que lo establecido por la ley de construcción ${ }^{58}$. Por ejemplo, bien podría argumentarse que cualquier construcción realizada sin cumplir con las técnicas antisísmicas de "disipación” o "aislamiento” supondrían actuaciones imprudentes. Lo que podría representar un argumento para zanjar de antemano cualquier "duda razonable" sobre la evitabilidad del resultado.

Ante nuestra consideración se podría sin embargo replicar que, antes aun, sería más oportuno preguntarnos si el modelo de resultado es realmente el paradigma de intervención más adecuado. En este sentido, se ha argumentado que, en lugar que manipular su estructura, se podrían tipificar modelos de peligro exigentes infracciones tan graves o temerarias como para ser definidas "criminales" 59.

Sin embargo, cabe observar que la oportunidad de abandonar la exigencia de la evitabilidad no significa renunciar al desvalor de resultado y convertir subrepticiamente el delito de resultado en un delito de peligro ${ }^{60}$ : como vimos, el nexo de causalidad en los delitos comisivos ya permite considerar como "propio" del sujeto el hecho realizado; y en cuanto a los delitos omisivos impropios, para que pueda hablarse de "comisión por omisión", un

\footnotetext{
55 Entre todos, Donini (2011) P. 533.

56 “(...) allí donde su observancia ciertamente aumenta claramente la posibilidad de salvaguarda del bien jurídico, pero no la garantiza con absoluta seguridad”: Roxin (1997) pp. 380-1.

57 Roxin (1997) p. 381.

58 Sobre la doctrina que defiende el estándar de la "mejor ciencia y experiencia", en sentido crítico, PERIN (2014) pp. 1401-1404; Perin (2016b) pp. 152 y ss., 157-159.

59 Así, p. ej., Veneziani (2003) pp. 225-6; Frisch (2004) p. 546; Eusebi (2011) pp. 963 y ss.

60 Así, en cambio, entre otros: Frisch (2004) pp. 594-5; Donini (2006) p. 107.
} 
Perin, Andrea "La relevancia de los cursos causales hipotéticos en la imputación normativa del resultado ..."

resultado lesivo - perteneciente al ámbito de protección de la posición de garante- debe haberse efectivamente realizado ${ }^{61}$.

Además, habría que considerar las implicaciones político-criminales que la adopción de nuevos tipos de peligro llevaría consigo, atendiendo a las características de cada sector de "riesgo permitido" y responsabilidad. No es lo mismo prever delitos de peligro en materia ambiental ${ }^{62}$ o para la prevención de riesgos laborales ${ }^{63}$, y en materia de responsabilidad médica. Los intereses, los actores, las fuentes y los mecanismos de producción de resultados lesivos, además de otros factores político-criminalmente relevantes, son distintos.

Refiriéndonos en particular a la mala praxis médica, cabe recordar que al facultativo que "incurriere en descuido culpable en el desempeño de su profesión, sin causar daño a las personas", ya se le puede castigar a título de falta por mera negligencia, sobre la base del art. 494, inc. 10, del Código Penal chileno. Se trata en realidad de una disposición que prácticamente no recibiría aplicación. No obstante, tampoco sería recomendable prever otro tipo, complementario a este y al delito de resultado, centrado -como se ha planteado también en la doctrina más reciente ${ }^{64}$ - en la realización de "tratamientos médicos arbitrarios" ${ }^{65}$. En efecto, cualquier vulneración del consentimiento, aun sin infracción del cuidado debido y/o consecuencias lesivas, podría adquirir de ese modo relevancia penal ${ }^{66}$. Pero esto podría fomentar aún más cierta tendencia a desnaturalizar el consentimiento informado, institución jurídica concebida como expresión y garantía de la autonomía del paciente ${ }^{67}$, convirtiéndolo en un instrumento de "traspaso" de responsabilidad y, en última instancia, de "medicina defensiva" 68 .

Desde luego, no se trata de renunciar a la imposición de deberes de información a los médicos; ni desconocer que el consentimiento "constituye per se un requisito del acto médico" ${ }^{69}$. Sin embargo, hay que reconocer que el alcance de dichos deberes no resulta suficientemente determinado ${ }^{70}$. Por ello, vincular directamente su cumplimiento a la imputación de responsabilidad penal expondría a los profesionales a mayores riesgos, a una situa-

${ }^{61}$ Corcoy (1989) p. 516; Viganò (2009) p. 1719.

62 Véase Matus et al. (2018) pp. 823-4.

63 Solución cuya utilidad práctica parece en todo caso relativa: Perin (2016a) pp. 9 y ss. Cfr. sin embargo la propuesta de lege ferenda planteada en Argentina por Gallo (2018) pp. 505 y ss.

${ }^{64}$ Rodríguez (2017) pp. 50 y ss.

65 Ver Romeo (2011) pp. 323 y ss.

66 Argumenta en cambio MaYer (2011) pp. 382-3, que "mientras el ordenamiento jurídico chileno carezca de una norma que castigue penalmente las denominadas intervenciones médicas arbitrarias, debe dársele a los tipos penales que castigan las lesiones corporales la interpretación más acorde con el respeto de la autonomía del paciente en lo que dice relación con su incolumidad o intangibilidad corporal". Lo que supone asumir que "las intervenciones médicas no consentidas que afecten la integridad corporal del paciente, independientemente de su adecuación a la lex artis médica, tendrán que considerarse como lesiones corporales punibles".

${ }^{67}$ Sobre autonomía, consentimiento y responsabilidad, en este medio: HernÁNDEZ (2010) pp. 167 y ss.; MAYER (2011) pp. 373 y ss.; De LA MAZA (2017) pp. 112 y ss.

68 Sobre el fenómeno en cuestión, para más referencias, Perin (2018b) pp. 865 y ss.

69 Como reconoce también la jurisprudencia nacional citada por DE LA MAZA (2017) p. 126, quien sin embargo nos advierte acerca de los peligros de una concepción "idealizada” o poco "realista" del fenómeno.

70 “¿qué alternativas de tratamiento y qué riesgos deben informarse?” Como señala De la MaZa (2017) p. 123, la respuesta a esta pregunta no resulta sencilla. 
ción de mayor inseguridad, desviándolos del objetivo principal representado por el bien del paciente en pos de condiciones de mayor protección frente a la aleatoriedad de la sanción.

\section{La re-descripción del resultado objeto del Juicio de imputación. El error DE DIAGNÓSTICO ENTRE EL DAÑO FÍSICO Y EL PERJUICIO FUNCIONAL}

La oportunidad de abandonar el criterio de la evitabilidad se puede apreciar también abordando el problema de la "re-descripción" del resultado.

Volvamos una vez más a nuestro ejemplo de mala praxis y supongamos que, conforme al peritaje a disposición del juez, un diagnóstico tempestivo hubiera podido evitar la completa atrofia muscular (con "probabilidad rayana a la certeza"), pero no la definitiva disfunción de la articulación afectada.

Ahora bien, si se considerara como resultado relevante la lesión muscular irreversible, esto es, el daño físico como tal y en su especificidad, se podría fácilmente argumentar su imputación (puesto que el resultado hic et nunc resultaría evitable). En cambio, considerando relevante la grave reducción de la movilidad articular, es decir, el daño funcional, el resultado podría estimarse inevitable, lo que nos llevaría a excluir la imputación normativa del mismo (en efecto, pese a la evitabilidad del daño físico hic et nunc, el daño funcional resultaría inevitable).

En nuestra opinión, frente al problema de la re-descripción del resultado, ninguna solución puede estimarse correcta a priori. Se plantea, de nuevo, una cuestión de oportunidad

Se podría por ejemplo sostener que, en vez de renunciar al nexo fuerte de la evitabilidad (especialmente en la omisión impropia), sería en cambio necesario considerar el resultado siempre en su "específica dimensión en el tiempo y el espacio, o sea, hic et nunc", ya que "sólo considerando el resultado con suficiente precisión" se evitaría "restringir de forma excesiva el ámbito de la responsabilidad penal"71. Solo de esta forma, además, el criterio de la evitabilidad no supondría una probatio diabolica.

Sin embargo, en muchas ocasiones el resultado hic et nunc no se puede distinguir claramente de otros alternativos y aún hipotéticos, más o menos hic et nunc.

Este problema no se plantea, por ejemplo, ante el "caso de la novocaína”. Como ya recordamos $(\$ I V)$, según la versión considerada generalmente en la discusión doctrinaria, el médico inyectó cocaína en vez de novocaína y el paciente falleció; sin embargo, se conoce después que, aunque se hubiese aplicado el anestésico correcto (la novocaína), el paciente hubiese fallecido por una intolerancia a dicha sustancia. Aquí, en efecto, el evento alternativo-hipotético (irreal) de la muerte por inyección de novocaína no excluye de ninguna manera la atribución del resultado (real) dado por el fallecimiento provocado por inyección causante e imprudente de cocaína. Los dos cursos causales - uno real, el otro hipotético- se pueden distinguir claramente y no se ven razones para excluir la imputación del primero ante la hipotética realización del segundo ${ }^{72}$.

Nuestro caso de error de diagnóstico, en cambio, es cualitativamente distinto. En efecto, además de ser inevitable el mismo perjuicio funcional al bien jurídico, la identifi-

71 Veneziani (2003) pp. 129-131.

72 En este sentido, pero a propósito del "caso del guardagujas”, Mañalich (2014) pp. 58 y ss. 
cación del resultado (respecto de otros hipotéticos de la misma especie) puede revelar una diferencia absolutamente mínima: por ejemplo, en la hipótesis que se compruebe una atrofia muscular de grado 8 (en una escala hipotética de 10), allí donde la conducta alternativa diligente (el diagnóstico tempestivo) hubiese dejado el paciente con una atrofia de grado 7 , esto es, ligeramente menos avanzada, pero asimismo invalidante e irreversible. La pregunta es -ella sí- inevitable: ¿sería esta diferencia de grado o entidad del daño (del mismo género) suficiente para sostener la imputación del resultado? ¿Y hasta qué punto, es decir, hasta qué nivel mínimo de divergencia?

El problema es que, mientras que en el caso de la novocaína y otros parecidos-como el "caso del guardagujas"73 - los resultados reales e hipotéticos, pero del mismo género, resultan claramente diversos, en otros -como el ejemplo de error de diagnóstico aquí considerado- la diferencias entre el evento hic et nunc (no evitado) y otro hipotético (resultante de la realización de una conducta conforme al cuidado debido) podrían ser tan mínimas y funcionalmente insignificantes como para hacernos dudar que una cuestión de imputación se pueda resolver de forma plenamente satisfactoria acudiendo al criterio tradicional; máxime teniendo presente que dicha imputación corresponde a una imputación de carácter penal, con las consecuencias que ello acarrea ${ }^{74}$.

En el fondo, el criterio de la evitabilidad se defiende, dada su caracterización causalista, por ser aparentemente el más garantista. Pero ¿cumple con esa función garantista un criterio que permite imputar un evento ante la hipotética realización de otro casi-totalmente idéntico y funcionalmente equivalente?.

\section{CONCLUSIONES}

Replanteémonos entonces la misma cuestión: ¿realmente la exigencia de la evitabilidad (rayana a la certeza, de un resultado más o menos hic et nunc) representa el mejor instrumento para evitar una expansión iliberal de la responsabilidad imprudente?

La tesis defendida consiste en permitir la imputación normativa del resultado a la conducta imprudente en cuanto el incumplimiento del cuidado debido haya generado un aumento del riesgo (tratándose de comisión), o bien, haya disminuido las oportunidades de preservación del bien jurídico (en las hipótesis de comisión por omisión) ${ }^{75}$. Se trata de una solución intermedia $-y$, en este sentido, compromisoria- entre dos planteamientos que, en nuestra opinión, pretenden lograr algo que no pueden conseguir.

La teoría de la evitabilidad responde a la necesidad axiológica de evitar retornos a formas de responsabilidad objetiva (sub-especie de versari in re illicita). Sin embargo, esta doctrina no define de forma adecuada la relación entre los criterios de imputación normativa, esto es, la estructura del nexo de riesgo; en particular, no aclara que, si se plantea el problema de la evitabilidad, ello significa que, antes aún, no se ha podido precisar exac-

\footnotetext{
73 Tratado por Mañalich (2014) pp. 58 y ss.

74 Cfr. Mañalich (2014) pp. 64 y ss.

75 Defienden imputaciones omisivo-imprudentes con aumento del riesgo también mínimo, CorCOY (1989) pp. 508 y ss., 512, 521; BarTOLI (2010) pp. 47 y ss., 103 y ss., 106.
} 
tamente el alcance del ámbito de protección de la norma infringida. Además, no valora la oportunidad de asegurar la vigencia de reglas de cuidado "impropias" - pero posiblemente eficaces- respecto de su ámbito de aplicación.

Por su parte, la doctrina que sostiene la irrelevancia de los cursos causales hipotéticos, si bien configura de forma adecuada la relación lógica y dogmática entre los juicios que permiten establecer si hay nexo de riesgo, tampoco considera la imposibilidad de averiguar si el resultado pertenece realmente al ámbito de protección de la norma infringida. En realidad, la sucesiva pregunta acerca de lo que hubiese pasado si el agente hubiese cumplido el cuidado debido responde a la necesidad de comprobar ex post la efectiva posibilidad de preservación. De lo contrario, el riesgo de condenar bajo la aparente pertenencia del evento al ámbito de protección de la norma, pero sin ninguna posibilidad de éxito, sería excesiva y seguramente incompatible con los principios básicos del derecho penal liberal.

En consideración de la estructura del injusto imprudente y desde una óptica más bien garantista, el criterio del "aumento del riesgo" puede evitar que los tribunales se dejen llevar por la tentación de fijar estándares de cuidado ajustados de forma instrumental a la segura (o más probable) evitabilidad del resultado. Al amparo del garantismo aparente de la condicio sine qua non aplicada al nexo de riesgo y a la omisión impropia (a la denominada "causalidad omisiva"), podrían legitimarse definiciones judiciales del deber de cuidado funcionales a que el resultado pueda valorarse evitable más allá de toda duda razonable (o con seguridad rayana a la certeza). En efecto, cuanto más elevada resulte la exigencia de cuidado determinada acudiendo al parámetro de la persona razonable y prudente, tanto más fácil será argumentar que la conducta alternativa hipotética hubiese evitado el resultado ${ }^{76}$; con todos los inconvenientes que esto puede suponer en términos de expansión de la responsabilidad penal, sobre todo cuando se trate de exigencias de cuidado de formación judicial (es decir, atípicas ${ }^{77}$ ).

Una vez abandonadas las impracticables -y a su vez inciertas- teorías de inspiración causal, y re-ubicada la cuestión en el plano de la imputación normativa, la valoración acerca del desvalor de la conducta volvería a representar el momento determinante para la atribución de la responsabilidad ${ }^{78}$; un desvalor de la conducta que debería suponer, para cumplir realmente con el principio de subsidiariedad penal, una infracción especialmente calificada del deber de cuidado. Esto es, una imprudencia "grave" o "temeraria"79.

\footnotetext{
76 En términos semejantes, Perin (2018a) p. 47.

77 Sobre esta noción, Perin (2017) pp. 227 y ss., 237 y ss.; PERIN (2018b) pp. 886 y ss., 888-9. Cfr. las acertadas reflexiones de Rosas (2012) pp. 57 y ss., quien, comentando un caso de error de diagnóstico y acudiendo a la noción de "lex artis ad hoc", hace ver con toda claridad la necesidad de valorar de forma muy rigurosa la exigibilidad ex ante de una conducta alternativa más eficaz, para poder justificar una imputación de responsabilidad ex art. 491 CP.

78 En este sentido también Viganò (2009) p. 1724.

79 Cfr. sin embargo la definición de "imprudencia temeraria” del art. 13 del Anteproyecto de Código Penal de 17 de octubre 2018: "cuando el sujeto hubiera podido evitar la realización del delito empleando la mínima diligencia que le era exigible de acuerdo con sus circunstancias”.
} 


\section{BIBLIOGRAFÍA CITADA}

ANGIOnI, Francesco (2006): "Note sull'imputazione dell'evento colposo con particolare riferimento all'attività medica", Studi in onore di Giorgio Marinucci, Tomo II (Milano, Giuffrè) pp. 1279-1333.

Bartoli, Roberto (2010): Il problema della causalità penale. Dai modelli unitari al modello differenziato (Torino, Giappichelli).

Bricola, Franco (1960): Dolus in re ipsa. Osservazioni in tema di oggetto e di accertamento del dolo (Milano, Giuffrè).

Bustos Ramírez, Juan y Hormazábal Malarée, Hernán (1980-81): "Significación social y tipicidad”, Estudios penales y criminológicos, vol. 5: pp. 9-42.

Cadoppl, Alberto (2011): “Omissione, liberalismo e paternalismo. Il 'caso' dell'omissione di soccorso", Studi in onore di Mario Romano, Tomo III (Milano, Giuffrè) pp. 1311-1354.

Cancio Meliá, Manuel (2001): Conducta de la víctima e imputación objetiva en Derecho penal. Estudio sobre los ámbitos de responsabilidad de victima y autor en actividades arriesgadas (Barcelona, Bosch).

Carnevali Rodríguez, Raúl (2002): "El delito de omisión. En particular la comisión por omisión”, Revista de Derecho de la Universidad Católica del Norte, vol. 9: pp. 69-80.

Carnevali Rodríguez, Raúl (2008): "Un examen a los problemas de relación de causalidad y de imputación objetiva conforme a la doctrina penal chilena”, en VARGAS PINTO, Tatiana (edit.), La relación de causalidad. Análisis de su relevancia en la responsabilidad civil y penal (Santiago, Universidad de los Andes) pp. 223-240.

Castaldo, Andrea (1989): L'imputazione oggettiva nel delitto colposo d'evento (Napoli, Jovene).

Castronuovo, Donato (2009): La colpa penale (Milano, Giuffrè).

Contesse Singh, Javier (2017): "La omisión impropia como hecho punible. Acerca de la incorporación de una regla general de punibilidad de los así llamados "delitos de omisión impropia” en el Anteproyecto del Nuevo Código Penal”, en Ambos, Kai, et al. (coords.), Reformas penales (Santiago, Der Ediciones) pp. 11-49.

Corcoy Bidasolo, Mirentxu (1989): El delito imprudente. Criterios de imputación del resultado (Barcelona, PPU).

Cuadrado Ruiz, María Ángeles (1997): “La comisión por omisión como problema dogmático”, Anuario de derecho penal y ciencias penales, vol. 50: pp. 387-456.

De la Maza Gazmuri, Íñigo (2017): “Consentimiento informado, un poco de realismo", Revista de Derecho (Valdivia), vol. XXX, N²: pp. 111-131.

De Vero, Giancarlo (2006): “Disvalore d'azione e imputazione dell'evento in un'aggiornata costruzione separata dei tipi criminosi”, Studi in onore di Giorgio Marinucci (Milano, Giuffrè) pp. 1487-1524.

Donini, Massimo (1989): "Lettura sistematica delle teorie dell'imputazione oggettiva dell'evento", Rivista italiana di diritto e procedura penale, vol. 32: pp. 588-638; 11141153.

Donini, Massimo (1999): "La causalità omissiva e l'imputazione "per l'aumento del rischio". Significato teorico e pratico delle tendenze attuali in tema di accertamenti ezio- 
logici probabilistici e decorsi causali ipotetici", Rivista italiana di diritto e procedura penale, vol. 42: pp. 32-85.

Donini, Massimo (2004): Il volto attuale dell'illecito penale. La democrazia penale tra differenziazione e sussidiarietà (Milano, Giuffrè).

Donini, Massimo (2006): Imputazione oggettiva dell'evento. "Nesso di rischio» e responsabilità per fatto proprio (Torino, Giappichelli).

Donini, Massimo (2011): "Il garantismo della condicio sine qua non e il prezzo del suo abbandono. Contributo all'analisi dei rapporti tra causalità e imputazione", Rivista italiana di diritto e procedura penale, vol. 54: pp. 494-535.

Engisch, Karl (1931): Die Kausalität als Merkmal der strafrechtlichen Tatbestände (Tübingen, Mohr).

Eusebi, Luciano (2011): "La prevenzione dell'evento non voluto. Elementi per una rivisitazione dogmatica dell'illecito colposo e del dolo eventuale", Studi in onore di Mario Romano II (Napoli, Jovene) pp. 963-1003.

Feijóo SÁnchez, Bernardo José (2001): Resultado lesivo e imprudencia. Estudio sobre los límites de la responsabilidad penal por imprudencia y el criterio del "fin de protección de la norma de cuidado" (Barcelona, Bosch).

FIANDACA, Giovanni (1979): Il reato commissivo mediante omissione (Milano, Giuffrè).

FIANDACA, Giovanni (2006): "Riflessioni problematiche tra causalità e imputazione obiettiva, L'Indice Penale: pp. 945-963.

ForTi, Gabrio (1990): Colpa ed evento nel diritto penale (Milano, Giuffrè).

Frisch, Wolfgang (2004): Comportamiento típico e imputación del resultado (Madrid/Barcelona, Marcial Pons).

Frisch, Wolfgang (2006): "La teoría de la imputación objetiva del resultado: lo fascinante, lo acertado y lo problemático”, en Frisch, Wolfgang y Robles Planas, Ricardo (editores), Desvalorar e imputar. Sobre la imputación objetiva en Derecho penal (Montevideo/ Buenos Aires, B de f) pp. 1-60.

FrISCH, Wolfgang (2015): La imputación objetiva del resultado. Desarrollo, fundamentos y cuestiones abiertas (Barcelona, Atelier).

Gallo, Marcello (1960): "voce Colpa penale”, Enciclopedia del diritto, Tomo VII (Milano, Giuffrè) pp. 624-644.

Gallo, Patricia (2018): Riesgos penales laborales. Responsabilidad penal del empresario por riesgos, enfermedades y accidentes laborales (Buenos Aires, B de f).

Garrido Montt, Mario (1997): Derecho Penal. Parte General, Tomo III (Santiago, Editorial Jurídica de Chile).

Gimbernat Ordeig, Enrique (1985-6): “¿Que es la imputación objetiva?”, Estudios penales y criminológicos: pp. 167-185.

Gimbernat Ordeig, Enrique (1990): Delitos cualificados por el resultado y causalidad (Madrid, Centro de Estudios Ramón Areces, segunda edición).

Gimbernat Ordeig, Enrique (1994): "Causalidad, omisión e imprudencia”, Anuario de derecho penal y ciencias penales, vol. XLVII: pp. 5-60.

Gimbernat Ordeig, Enrique (2015): “Teoría de la evitabilidad versus teoría del aumento del riesgo", Anuario de derecho penal y ciencias penales, vol. LXVIII: pp. 21-62. 
Perin, Andrea "La relevancia de los cursos causales hipotéticos en la imputación normativa del resultado ..."

Gimbernat Ordeig, Enrique (2017): El comportamiento alternativo conforme a Derecho (Buenos Aires, B de f).

Grasso, Giovanni (1983): Il reato omissivo improprio. La struttura obiettiva della fattispecie (Milano, Giuffrè).

Grotto, Marco (2012): Principio di colpevolezza, rimproverabilità soggettiva e colpa specifica (Torino, Giappichelli).

HAAS, Volker (2016): "La doctrina penal de la imputación objetiva. Una crítica fundamental", InDret, $\mathrm{N}^{\circ}$ 1: pp. 1-32.

HaVa García, Esther (2002): La imprudencia inconsciente (Granada, Comares).

Hernández Basualto, Héctor (2010): "Consentimiento informado y responsabilidad penal médica: una relación ambigua y problemática", en DE la MAZA GAZMURi (coord.), Responsabilidad médica, Cuadernos de análisis jurídico (Santiago: Ediciones Universidad Diego Portales) pp. 167- 185.

Hernández Basualto, Héctor (2011): “Art. 10", en Couso Salas, Jaime y Hernández BAsualto, Héctor (directores), Código Penal Comentado. Parte General, Doctrina y Jurisprudencia (Santiago, LegalPublishing) pp. 7-104.

Honig, Richard M. (1930): "Kausalität und objektive Zurechnung”, en Hegler, A. (editor), Festgabe für Reinhard von Frank zum 70, Tomo I (Tübingen, Mohr) pp. 174-201.

LarenZ, Karl (1970): Hegels Zurechnungslehre und der Begriff der objektiven Zurechnung: Ein Beitrag zur Philosophie des kritischen Idealismus und zur Lehre von der «juristischen Kausalität» (Aalen, Scientia Verlag, primera edición de 1927).

Luzón Peña, Diego Manuel (2017): “Omisión impropia o comisión por omisión. Cuestiones nucleares: imputación objetiva sin causalidad, posiciones de garante, equivalencia (concreción del criterio normativo de la creación o aumento de peligro o riesgo) y autoría o participación", Libertas. Revista de la Fundación Internacional de Ciencias Penales, vol. 6: pp. 145-272.

LÜвBE, Weyma (1993): “Die Theorie der adäquaten Verursachung: Zum Verhältnis von philosophischem und juristischem Kausalitätsbegriff”, Zeitschrift für allgemeine Wissenschaftstheorie, vol. 24: pp. 87-102.

MAIWALD, Manfred (2018): "Non c'è dolo senza colpa. La teoria dell'imputazione oggettiva nella dottrina italiana”, Rivista italiana di diritto e procedura penale, vol. 61: pp. 1-20.

Mañalich, Juan Pablo (2014): Norma, causalidad y acción. Una teoría de las normas para la dogmática de los delitos de resultado puros (Madrid/Barcelona/Buenos Aires/São Paulo, Marcial Pons).

Mañalich, Juan Pablo (2015): "La imprudencia como estructura de imputación", Revista de Ciencias Penales, vol. XLII, No 3: pp. 13-36.

Maraver Gómez, Mario (2009): El principio de confianza en Derecho penal. Un estudio sobre la aplicación del principio de autorresponsabilidad en la teoría de la imputación objetiva (Cizur Menor, Civitas).

MARInUCCI, Giorgio (1965): La colpa per inosservanza di leggi (Milano, Giuffrè).

MarinuCCI, Giorgio (1991): "Non c’è dolo senza colpa. Morte della «imputazione oggettiva dell'evento» e trasfigurazione nella colpevolezza?", Rivista italiana di diritto e procedura penale, vol. 34: pp. 3-39. 
Martínez Escamilla, Margarita (1992): La imputación objetiva del resultado (Madrid, Edersa).

Martínez Escamilla, Margarita (1994): “¿Relevancia de los comportamientos alternativos conformes a Derecho en la imputación objetiva del resultado?”, en Gimbernat Ordeig, ET AL. (editores), Omisión e imputación objetiva en Derecho penal (Madrid, Universidad Complutense Madrid - Ministerio de Justicia e Interior) pp. 103-113.

Matus, Jean Pierre, Ramírez, María Cecilia y Castillo, Marcelo (2018): “Acerca de la necesidad de una reforma urgente de los delitos de contaminación en Chile, a la luz de la evolución legislativa del siglo XXI", Política Criminal, vol. 13, № 26: pp. 771-835.

Mayer LuX, Laura (2011): "Autonomía del paciente y responsabilidad penal médica", Revista de Derecho de la Pontificia Universidad Católica de Valparaíso, vol. XXXVII: pp. 371-413.

Mayer Lux, Laura y Vera Vega, Jaime (2015): "Caso "Alto Río". SCS, 4/04/2014, Rol No 185-2014", en Vargas, Tatiana (directora), Casos destacados Derecho penal - Parte general (Santiago, Thomson Reuters) pp. 535-555.

Mir Puig, Santiago (2003): "Significado y alcance de la imputación objetiva en Derecho penal”, en Revista Electrónica de Ciencia Penal y Criminología, No 5: pp. 1-19.

Muñoz Conde, Francisco y García Arán, Mercedes (2010): Derecho penal. Parte general (Valencia, Tirant Lo Blanch).

Náquira Riveros, Jaime (2017): Derecho Penal Chileno. Parte General, Tomo II (Santiago, Thomson Reuters).

NaVAS, Iván (2015): "Acción y omisión en la infracción de deberes negativos en derecho penal”, Política Criminal, vol. 10, N²0: pp. 678-693.

Novoa Monreal, Eduardo (1984): Fundamentos de los delitos de omisión (Buenos Aires, Depalma).

Perin, Andrea (2014): "La crisi del "modello nomologico" fra spiegazione e prevedibilità dell'evento nel diritto penale. Note introduttive e questioni preliminari sul fatto tipico colposo", Rivista italiana di diritto e procedura penale, vol. 57, N³: pp. 1371-1409.

Perin, Andrea (2016a): "La contribución de la víctima y la imputación objetiva del resultado en la teoría del delito imprudente. Un estudio comparado en materia de prevención de riesgos laborales", Revista Electrónica de Ciencia Penal y Criminología, No18: pp. 1-27.

Perin, Andrea (2016b): "Conocimientos científicos, tecnologías convergentes y derecho penal. Reflexiones metodológicas en materia de causalidad, imprudencia, imputabilidad y peligrosidad”, en Romeo Casabona, Carlos María (editor), Tecnología convergentes: desafios éticos y jurídicos (Bilbao/Granada, Cátedra de Derecho y Genoma Humano Comares) pp. 145-176.

Perin, Andrea (2017): "La condotta lesiva colposa. Una prospettiva ricostruttiva", Politica Criminal, vol. 12, № 23: pp. 207-266.

Perin, Andrea (2018a): "L'imputazione oggettiva dell'evento per omissione impropria. Argomenti a favore della «diminuzione di chances»", Archivio penale, $\mathrm{N}^{\circ} 2$ (web): pp. 1-47. 
Perin, Andrea "La relevancia de los cursos causales hipotéticos en la imputación normativa del resultado ..."

Perin, Andrea (2018b): "La redefinición de la culpa (imprudencia) penal médica ante el fenómeno de la medicina defensiva. Bases desde una perspectiva comparada”, Política Criminal, vol. 13, No 26: pp. 858-903.

Politoff, Sergio, Matus, Jean y Ramírez, Cecilia (2003): Lecciones de Derecho Penal Chileno. Parte General (Santiago, Editorial Jurídica de Chile).

Puppe, Ingeborg (2010): "La teoría de la imputación objetiva y su aplicación", Revista de Derecho Penal, $\mathrm{N}^{\circ}$ 1: pp. 59-105.

Robles Planas, Ricardo (2006): "Conducta típica, imputación objetiva e injusto penal. Reflexiones al hilo de la aportación de Frisch a la teoría del tipo”, en FrISCH, Wolfgang y Robles Planas, Ricardo (editores), Desvalorar e imputar. Sobre la imputación objetiva en Derecho penal (Montevideo/Buenos Aires, B de F) pp. 61-175.

Robles Planas, Ricardo (2015): "La «teoría de la imputación objetiva»: algunas consideraciones sobre sus orígenes y su futuro", en FRISCH, Wolfgang, La imputación objetiva del resultado (Barcelona, Atelier).

RodrígueZ VÁsqueZ, Virgilio (2017): "El delito de tratamiento médico arbitrario", Revista Electrónica de Ciencia Penal y Criminología, N 19-3: pp. 1-59.

Rojas Aguirre, Luis Emilio (2008): "La comisión por omisión en Alemania", Sección "Sistemas penales comparados”, Revista Penal, No 21: pp. 192-195.

Rojas Aguirre, Luis Emilio (2010): "Lo subjetivo en el juicio de imputación objetiva: ¿aporía teórica?”, Revista de Derecho (Valdivia), vol. 23: pp. 233-254.

Rojas Aguirre, Luis Emilio (2018): "Delitos de omisión entre libertad y solidaridad", Política Criminal, vol. 13, No 26: pp. 682-738.

Romeo Casabona, Carlos María (2011): El médico y el Derecho Penal, Tomo I, La actividad curativa. Licitud y responsabilidad penal (Santa Fe, Rubinzal - Culzoni).

Rosas Oliva, Juan Ignacio (2012): "Responsabilidad penal del médico. Error de diagnóstico y lex artis", Razonamiento penal, $\mathrm{N}^{\circ}$ 1: pp. 57-63.

Roxin, Claus (1962): "Pflichtwidrigkeit und Erfolg bei fahrlässigen Delikten", Zeitschrift für die gesamte Strafrechtswissenschaft, vol. 74: pp. 411-444.

Roxin, Claus (1970): "Gedanken zur Problematik der Zurechnung im Strafrecht", en Festschrift für Richard M. Honig (Göttingen, Schwartz) pp. 132-146.

Roxin, Claus (1997): Derecho Penal. Parte General, Tomo I (Madrid, Editorial Civitas).

RudolphI, Hans-Joachim (1969): "Vorhersehbarkeit und Schutzzweck der Norm in der strafrechtlichen Fahrlässigkeitslehre”, JuS: pp. 549-557.

Schünemann, Bernd (1975): "Moderne Tendenzen in der Dogmatik der Fahrlässigkeit-und Gefährdungsdelikte”, Juristische Arbeitsblätter (Zeitschrift): pp. 435-444, 511-516, 575584, 647-656, 715-724, 787-798.

SGUBbI, Filippo (1975): Responsabilità penale per omesso impedimento dell'evento (Padova, Cedam).

Silva Sánchez, Jesús María (2003): El delito de omisión. Concepto y sistema (Montevideo/ Buenos Aires, B de F, segunda edición).

Stella, Federico (1988): La nozione penalmente rilevante di causa: la condizione necessaria, en Rivista italiana di diritto e procedura penale, vol. 31: pp. 1217-1268. 
Summerer, Kolis (2013): Causalità ed evitabilità. Formula della condicio sine qua non e rilevanza dei decorsi causali ipotetici nel diritto penale (Pisa, ETS).

Ulsenheimer, Klaus (1965): Das Verhältnis zwischen Pflichtwidrigkeit und Erfolg bei den Fahrlässigkeitsdelikten (Bonn, Röhrscheid).

Vargas Pinto, Tatiana (2017): Responsabilidad Penal por Imprudencia Médica (Santiago, Der Ediciones).

Veneziani, Paolo (2003): Regole cautelari "proprie" ed “improprie" nella prospettiva delle fattispecie colpose causalmente orientate (Padova, Cedam).

Viganò, Francesco (2009): "Riflessioni sulla cd. "causalità omissiva” in materia di responsabilità medica, Rivista italiana di diritto e procedura penale”, vol. 52: pp. 1679-1725.

Wolter, Jürgen (1981): Objektive und personale Zurechnung von Verhalten, Gefahr und Verletzung in einem funktionellen Straftatsystem (Berlin, Duncker \& Humblot).

\section{NORMAS CITADAS}

Art. 13, Anteproyecto de Código Penal (17 de Octubre 2018).

Art. 491, Código Penal de Chile.

Art. 494, inc. 10, Código Penal de Chile. 
